
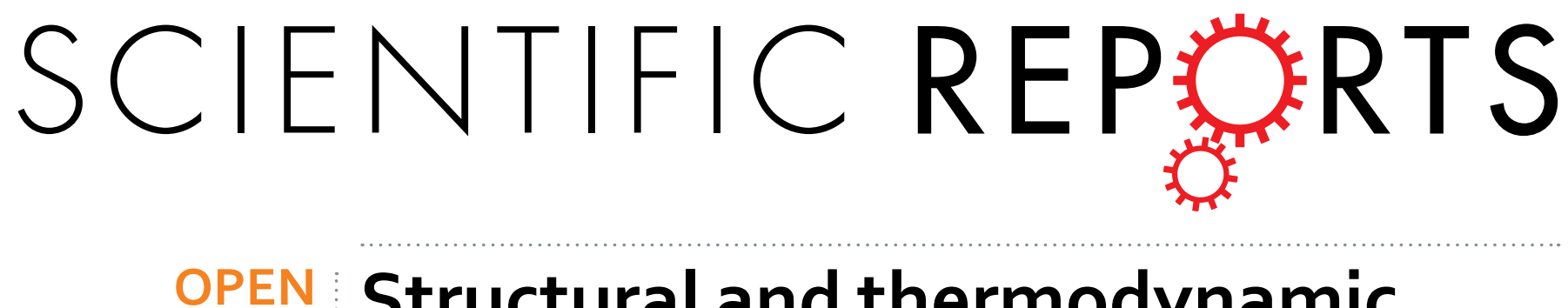

\title{
Structural and thermodynamic basis of proline-induced transmembrane complex stabilization
}

In membrane proteins, proline-mediated helix kinks are indispensable for the tight packing of transmembrane (TM) helices. However, kinks invariably affect numerous interhelical interactions, questioning the acceptance of proline substitutions and evolutionary origin of kinks. Here, we present the structural and thermodynamic basis of proline-induced integrin $\alpha$ llb $\beta 3$ TM complex stabilization to understand the introduction of proline kinks in membrane proteins. In phospholipid bicelles, the A711P substitution in the center of the 33 TM helix changes the direction of adjacent helix segments to form a $35 \pm 2^{\circ}$ angle and predominantly repacks the segment in the inner membrane leaflet due to a swivel movement. This swivel repacks hydrophobic and electrostatic interhelical contacts within intracellular lipids, resulting in an overall TM complex stabilization of $-0.82 \pm 0.01 \mathrm{kcal} / \mathrm{mol}$. Thus, proline substitutions can directly stabilize membrane proteins and such substitutions are proposed to follow the structural template of integrin $\alpha$ Ilb33(A711P).

In the evolution of globular proteins, structural complexity and functionality can be increased by combining independently folding protein domains ${ }^{1,2}$. In contrast, in membrane proteins, individual intramembraneous domains are not apparent beyond transmembrane (TM) helices and an increase in complexity necessitates an increase in the overall number of TM helices. In the human genome, multi-pass (polytopic) membrane proteins are predicted to exhibit an average number of $6.6 \mathrm{TM}$ helices and to contain up to $37 \mathrm{TM}$ helices. To maximize the available structural repertoire, TM helices must cross each other at non-zero angles. However, with increasing distance from helix-helix crossing points, sidechains will lose interhelical contacts. Apparently, this downside is compensated by introducing helix kinks and by wedging either non-helical residues or additional helices into a helix-helix interface (Fig. 1). In contrast to wedges, helix kinks may be created by a single point mutation that introduces proline. The fusion of the proline sidechain to the backbone nitrogen atom and the loss of helical hydrogen bonding introduces a helix kink of varying severity ${ }^{3-7}$. Mutations to proline consequently may have played a central role in the evolution of membrane proteins.

Indirect support for this hypothesis is abundant. Inspection of membrane protein structures reveals that helix kinks are frequently centered around proline residues (Fig. 1a,b) ${ }^{4,6,8,9}$. Even for non-proline kinks, it is likely that a proline first initiated this conformation but became redundant when tertiary contacts solidified the kink conformation ${ }^{10}$. The important function of prolines further extends to preventing membrane protein misfolding ${ }^{11}$. Despite the benefit of prolines, their evolutionary origin is unclear as proline substitutions are difficult to establish. TM sequences from the Human Gene Mutation Database have one of the highest phenotypic incidences for proline substitutions ${ }^{12}$. Moreover, in the seven-helix bundle protein bacteriorhodopsin, 15 proline substitutions were examined and all were found to destabilize the protein ${ }^{13}$. Similarly, in the glycophorin A homodimer, proline scanning of the TM helix only destabilized the protein ${ }^{14}$. While protein stability may be recoverable by subsequent mutations, the extensive structural perturbations created by the sidechain geometry of proline invariably make such a pathway challenging. In comparison, an initially stabilizing kink followed by destabilizing, adaptive

Department of Biochemistry \& Molecular Biology and Zilkha Neurogenetic Institute, Keck School of Medicine, University of Southern California, 1501 San Pablo Street, Los Angeles, CA 90033, USA. 'Present address: Laboratory of Chemical Physics, National Institute of Diabetes and Digestive and Kidney Diseases, National Institutes of Health, Bethesda, MD 20892, USA. Correspondence and requests for materials should be addressed to T.S.U. (email: tulmer@usc.edu) 

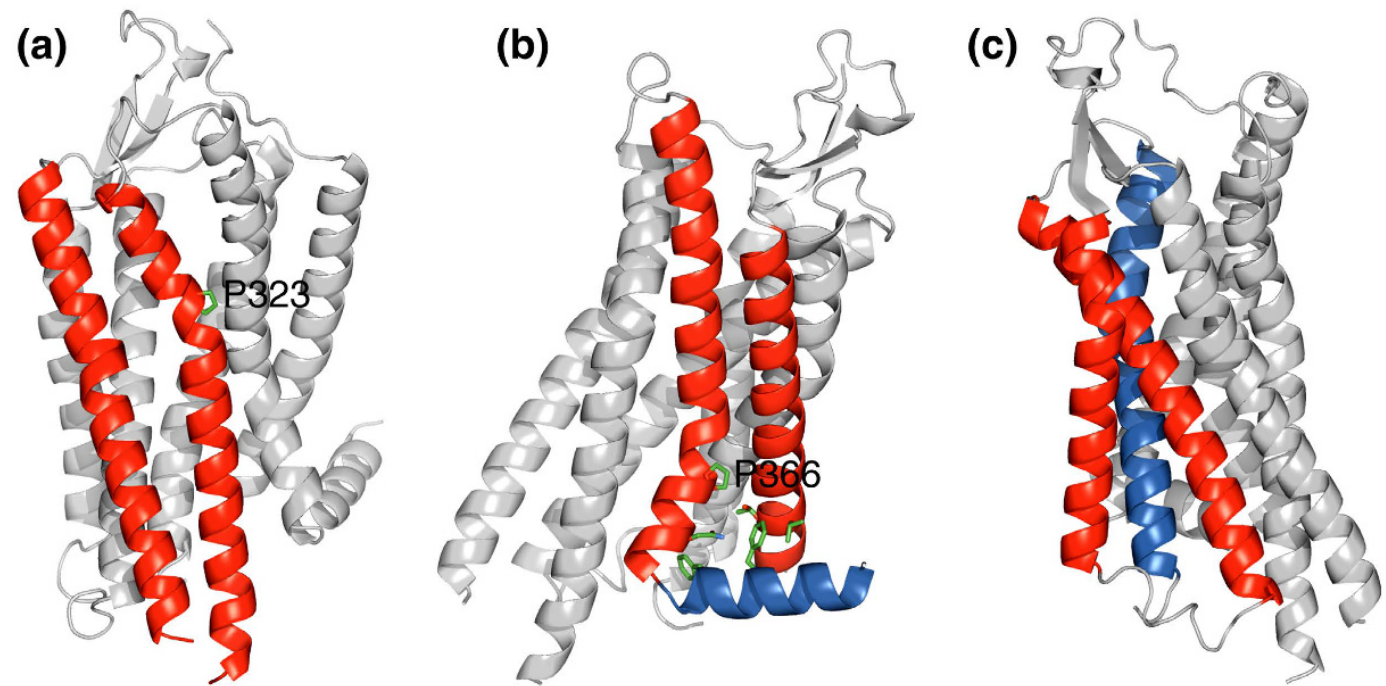

Figure 1. Transmembrane helix-helix interfaces in the neurotensin receptor 1. (a) Proline kink-mediated helix-helix packing. (b,c) Wedging of either non-helical residues or an additional helix into a helix-helix interface. PDB entry 4 bwb was used ${ }^{33}$.

\begin{tabular}{|c|c|c|c|c|c|}
\hline Peptides & $\mathrm{K}_{\mathrm{XY}}^{\mathrm{a}}$ & $\Delta \mathrm{H}^{\circ}[\mathrm{kcal} / \mathrm{mol}]$ & $\mathrm{T} \Delta \mathbf{S}^{\circ}[\mathbf{k c a l} / \mathbf{m o l}]$ & $\Delta \mathrm{G}^{\circ}[\mathrm{kcal} / \mathrm{mol}]$ & $\Delta \Delta \mathbf{G}^{\circ, \mathbf{b}}[\mathrm{kcal} / \mathrm{mol}]$ \\
\hline$\alpha I I b+\beta 3^{c}$ & $3250 \pm 60$ & $-16.0 \pm 0.1$ & $-11.1 \pm 0.1$ & $-4.84 \pm 0.01$ & - \\
\hline$\alpha \mathrm{IIb}+\beta 3(\mathrm{~A} 711 \mathrm{P})$ & $12700 \pm 200$ & $-16.9 \pm 0.1$ & $-11.2 \pm 0.1$ & $-5.66 \pm 0.01$ & - \\
\hline$\alpha \operatorname{IIb}(G 972 A)+\beta 3$ & $1080 \pm 30$ & $-14.2 \pm 0.2$ & $-10.1 \pm 0.2$ & $-4.18 \pm 0.01$ & - \\
\hline$\alpha \operatorname{IIb}(\mathrm{G} 972 \mathrm{~A})+\beta 3(\mathrm{~A} 711 \mathrm{P})$ & $5500 \pm 300$ & $-16.2 \pm 0.3$ & $-11.0 \pm 0.3$ & $-5.16 \pm 0.03$ & $0.16 \pm 0.03$ \\
\hline$\alpha \mathrm{IIb}+\beta 3(\mathrm{~L} 712 \mathrm{~A})$ & $1900 \pm 50$ & $-12.0 \pm 0.1$ & $-7.4 \pm 0.1$ & $-4.52 \pm 0.01$ & - \\
\hline$\alpha \mathrm{IIb}+\beta 3(\mathrm{~A} 711 \mathrm{P} / \mathrm{L} 712 \mathrm{~A})$ & $4200 \pm 100$ & $-12.8 \pm 0.1$ & $-7.8 \pm 0.1$ & $-5.00 \pm 0.01$ & $-0.34 \pm 0.01$ \\
\hline$\alpha \mathrm{IIb}+\beta 3(\mathrm{~W} 715 \mathrm{Y})$ & $1300 \pm 40$ & $-14.2 \pm 0.2$ & $-9.9 \pm 0.2$ & $-4.30 \pm 0.02$ & - \\
\hline$\alpha \mathrm{IIb}+\beta 3(\mathrm{~A} 711 \mathrm{P} / \mathrm{W} 715 \mathrm{Y})$ & $2200 \pm 100$ & $-14.4 \pm 0.4$ & $-9.8 \pm 0.4$ & $-4.61 \pm 0.03$ & $-0.51 \pm 0.04$ \\
\hline$\alpha \operatorname{IIb}(\mathrm{R} 995 \mathrm{~A})+\beta 3^{\mathrm{c}}$ & $250 \pm 70$ & $-15 \pm 4$ & $-12 \pm 4$ & $-3.3 \pm 0.2$ & - \\
\hline$\alpha \operatorname{IIb}(\mathrm{R} 995 \mathrm{~A})+\beta 3(\mathrm{A711P})$ & $4000 \pm 300$ & $-5.6 \pm 0.2$ & $-0.59 \pm 0.2$ & $-4.98 \pm 0.04$ & $0.8 \pm 0.2$ \\
\hline
\end{tabular}

Table 1. Thermodynamic stability of mutant $\alpha \mathrm{IIb} \beta 3$ TM complexes. ${ }^{a}$ Measurements performed in $43 \mathrm{mM}$ DHPC, $17 \mathrm{mM}$ POPC, $25 \mathrm{mM} \mathrm{NaH} \mathrm{PO}_{4} / \mathrm{Na}_{2} \mathrm{HPO}_{4} \mathrm{pH} 7.4$ solution at $28^{\circ} \mathrm{C}$ (effective bicelle q-factor of 0.5 ).

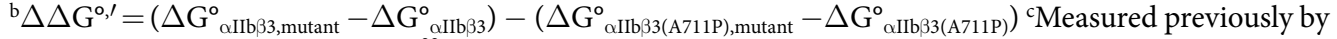
competitive binding experiments ${ }^{32}$, resulting in larger experimental uncertainties than direct measurements.

mutations appears more advantageous. Destabilizing mutations are abundant and therefore faster to occur in the critical time window after the initial mutation. Here, we provide experimental support for the second pathway to provide insight into the evolution and design principles of membrane proteins.

\section{Results and Discussion}

In the family of integrin adhesion receptors, the TM complex between $\alpha$ and $\beta$ subunits constrains the receptor in its inactive conformation ${ }^{15,16}$. Specifically, the inactive ectodomains and associated TM complex stabilize each other ${ }^{15}$. A substantial loss of $\alpha \beta$ TM affinity and the ensuing TM complex dissociation allows the ectodomains to rearrange, thereby activating the receptor to bind ligands. For example, the proline substitution L718P in the TM helix of the $\beta 3$ subunit is a disease-causing mutation in humans arising from spontaneous receptor activation ${ }^{17}$. This structural architecture of integrins makes the study of integrin $\alpha \beta$ TM complexes in isolation relevant to understanding their allosteric regulation. In the integrin $\alpha \operatorname{IIb} \beta 3$ receptor, we previously discovered the ability of $\beta 3(\mathrm{~A} 711 \mathrm{P})$ to compensate the activating $\beta 3(\mathrm{~K} 716 \mathrm{~A})$ substitution in an evolutionary selection screen ${ }^{18}$. If $\beta 3$ (A711P) indeed stabilizes the inactive receptor conformation, it must increase $\alpha \operatorname{IIb} \beta 3 \mathrm{TM}$ complex affinity by itself. Thus we determined the thermodynamic stability of the $\alpha \operatorname{IIb} \beta 3(\mathrm{~A} 711 \mathrm{P}) \mathrm{TM}$ complex in phospholipid bicelles ${ }^{19}$ by isothermal titration calorimetry. We found a stabilization of $-0.82 \pm 0.01 \mathrm{kcal} / \mathrm{mol}$ relative to the wild-type TM complex stability, termed $\Delta \mathrm{G}_{\mathrm{TM}}^{\circ}$, of $-4.84 \pm 0.01 \mathrm{kcal} / \mathrm{mol}$ (Table 1). Indeed, $\beta 3(\mathrm{~A} 711 \mathrm{P}$ ) is the first documented example of a stabilizing proline substitution in a membrane protein that we are aware of. It reveals that proline substitutions can increase the complexity of membrane proteins by directly stabilizing interhelical interactions.

To understand the basis of $\beta 3(\mathrm{~A} 711 \mathrm{P})$, we determined the structure of the $\alpha \operatorname{IIb} \beta 3(\mathrm{~A} 711 \mathrm{P}) \mathrm{TM}$ complex in isotropic phospholipid bicelles by multidimensional heteronuclear NMR spectroscopy. In the structure 
(a)

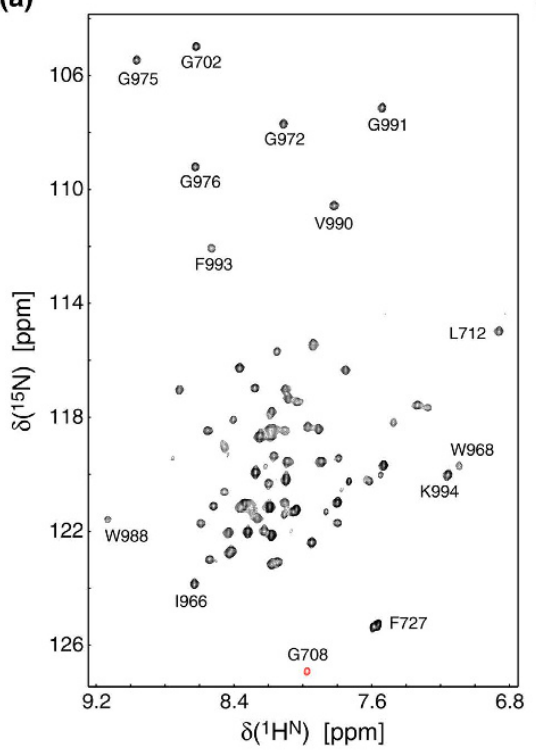

(b)

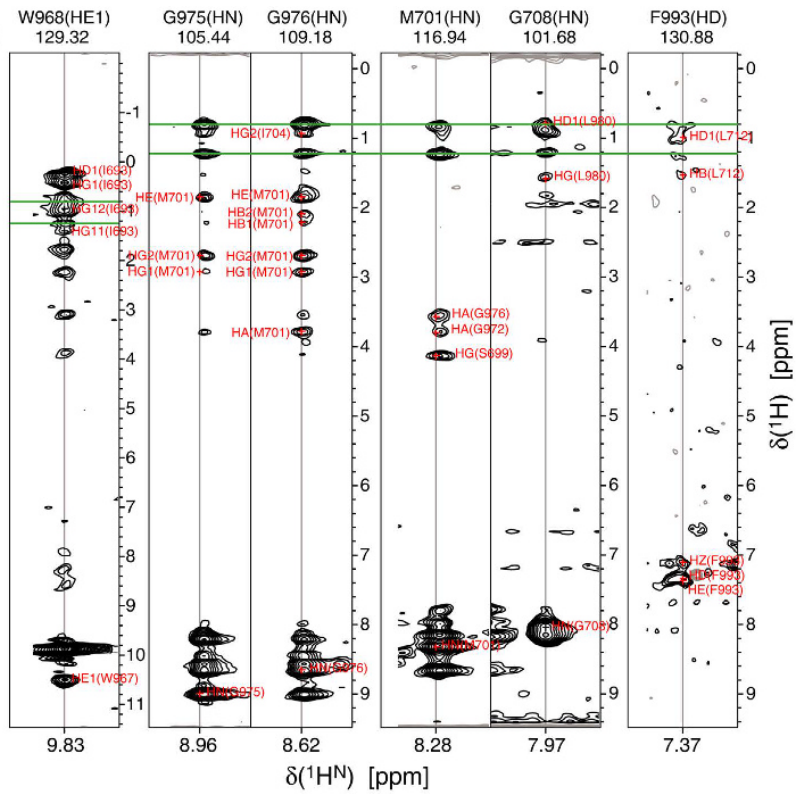

Figure 2. NMR spectra of the integrin $\alpha$ IIb33(A711P) TM complex. (a) TROSY-type H-N correlation spectrum of disulfide-linked ${ }^{2} \mathrm{H} /{ }^{13} \mathrm{C} /{ }^{15} \mathrm{~N}-\alpha \mathrm{IIb}(\mathrm{A} 963 \mathrm{C})-{ }^{2} \mathrm{H} /{ }^{13} \mathrm{C} /{ }^{15} \mathrm{~N}-\beta 3(\mathrm{G} 690 \mathrm{C} / \mathrm{A} 711 \mathrm{P})$. (b) 3D NOESY-TROSY strips of disulfide-linked ${ }^{2} \mathrm{H} /{ }^{15} \mathrm{~N}-\alpha \mathrm{IIb}(\mathrm{A} 963 \mathrm{C})-\beta 3(\mathrm{G} 690 \mathrm{C} / \mathrm{A} 711 \mathrm{P})$ and $\alpha \mathrm{IIb}(\mathrm{A} 963 \mathrm{C})-{ }^{2} \mathrm{H} /{ }^{15} \mathrm{~N}-\beta 3(\mathrm{G} 690 \mathrm{C} /$ $\mathrm{A} 711 \mathrm{P})$ illustrate interhelical NOEs. NOEs to protonated lipids are indicated by green lines. All spectra were recorded at $40^{\circ} \mathrm{C}$ and $700 \mathrm{MHz}$.

determination of the wild-type $\alpha \operatorname{IIb} \beta 3$ TM complex, we had used selectively methyl-labeled protein and deuterated lipids to obtain interhelical NOE distance restraints ${ }^{15}$. Upon inspecting this structure, we predicted that it is possible to detect a similar number of distance restraints by measuring NOEs between backbone ${ }^{1} \mathrm{H}^{\mathrm{N}}$ and sidechain ${ }^{1} \mathrm{H}$ nuclei across the helix-helix interface. We thus combined one perdeuterated and one protonated subunit in protonated lipids. Additionally, as described previously ${ }^{20}$, we cross-linked the complex outside of the TM region by a disulfide bond to maximize the concentration of dimer, to suppress residual monomer signals and to improve dimer lineshapes. This approach permitted the detection of interhelical NOEs up to ${ }^{1} \mathrm{H}^{\mathrm{N}}{ }^{1} \mathrm{H}^{\alpha}$ pairs (Fig. 2), albeit only in the vicinity of glycines packed in the dimerization interface. The reduced range of ${ }^{1} \mathrm{H}^{\mathrm{N}}-{ }^{1} \mathrm{H}$ as opposed to ${ }^{1} \mathrm{H}^{\mathrm{CH} 3}{ }_{-}^{1} \mathrm{H}$ distances is mitigated by the high rigidity of backbone ${ }^{1} \mathrm{H}^{\mathrm{N}}$ nuclei compared to sidechain ${ }^{1} \mathrm{H}^{\mathrm{CH} 3}$ nuclei. Moreover, it was further compensated by observing intersubunit NOEs to the indole ${ }^{1} \mathrm{H}^{\mathrm{N}}$ nuclei of $\alpha \mathrm{IIb}$ (W968) and $\beta 3$ (W715), which are located at the $\mathrm{N}$ - and C-helix termini, and by detecting NOEs to the aromatic ring of $\alpha \mathrm{IIb}$ (F993) in fractionally deuterated samples (Fig. 2). Membrane proteins show an abundance of aromatic residues in the membrane-water interface ${ }^{21,22}$, which makes the presented approach effective for the structure determination of membrane proteins with packed glycines in the presence of protonated lipids or detergents. Further structural restraints included $\mathrm{H}-\mathrm{N}$ residual dipolar couplings collected for the perdeuterated complex. An ensemble of 20 structures was calculated by simulated annealing with a coordinate precision of $0.33 \AA$ for backbone heavy atoms (Supplementary Figure 1 and Supplementary Table 1).

In the wild-type $\alpha \operatorname{Il} \beta \beta 3$ TM complex, two association motifs were differentiated ${ }^{15}$. The outer membrane clasp (OMC) is characterized by sidechain packing into the helix grooves created by $\alpha \mathrm{IIb}(\mathrm{G} 972), \alpha \mathrm{IIb}(\mathrm{G} 976)$ and $\beta 3$ (G708). The inner membrane clasp (IMC) is characterized by the wedging of $\alpha \mathrm{IIb}$ (Phe992-Phe993) to connect the separating TM helices and to maximize electrostatic $\alpha I \mathrm{Ib}($ Arg995)- $\beta 3$ (Asp723) interactions (Fig. 3a). In the $\alpha I I b \beta 3(A 711 P)$ TM complex, these interactions were maintained albeit with changes. The ${ }^{15} \mathrm{~N}$ chemical shift differences between $\alpha I I b$ when complexed with either $\beta 3$ or $\beta 3(\mathrm{~A} 711 \mathrm{P})$ illustrated that structural changes predominantly took place for IMC residues and residues that pack near the mutation site (Fig. 3b). The $\alpha$ IIb(W967-L979) helical segment was largely invariant, making it suitable to superimpose $\alpha \operatorname{IIb} \beta 3$ and $\alpha \operatorname{IIb} \beta 3(\mathrm{~A} 711 \mathrm{P})$ coordinates to illustrate long-range structural differences. Within the dimer, the A711P substitution caused a $35 \pm 2^{\circ}$ kink in the $\beta 3$ helix. The impact of this kink was minimized by maintaining $\alpha I$ Ib interhelical packing against $\beta 3(\mathrm{G} 708)$ while distributing the changes in $\beta 3$ helix directions to both the OMC and IMC (Fig. 3a). In the OMC, no significant rotation about the helix axis relative to wild type (swivel movement) took place (Fig. 3c). Changes in interhelical sidechain distances were apparently compensated by modifications of sidechain conformations (Fig. 3c). On the other hand, in the IMC changes in interhelical distance and swivel orientation were encountered. These changes altered $\alpha$ IIb contacts with $\beta 3$ residues L712, W715, K716, I719 and D723 in the dimerization interface and increased towards the C-terminus (Fig. 3c).

To achieve a quantitative context for discussing changes in sidechain contacts, we determined changes in thermodynamic stabilities of four point mutations between the $\alpha \operatorname{IIb} \beta 3(\mathrm{~A} 711 \mathrm{P})$ and $\alpha \operatorname{IIb} \beta 3 \mathrm{TM}$ complexes. Specifically, $\Delta \Delta \mathrm{G}^{\circ, \prime}=\left(\Delta \mathrm{G}^{\circ}{ }_{\alpha \mathrm{IIb} \beta 3 \text {,mutant }}-\Delta \mathrm{G}^{\circ}{ }_{\alpha \mathrm{IIb} \beta 3}\right)-\left(\Delta \mathrm{G}^{\circ}{ }_{\alpha \mathrm{IIb} \beta 3(\mathrm{~A} 711 \mathrm{P}) \text {,mutant }}-\Delta \mathrm{G}^{\circ}{ }_{\alpha \mathrm{IIb} \beta 3(\mathrm{~A} 711 \mathrm{P})}\right)$ was quantified to compare the disturbance created by a mutation relative to its respective $\alpha \operatorname{IIb} \beta 3$ and $\alpha \operatorname{IIb} \beta 3(\mathrm{~A} 711 \mathrm{P})$ reference structure. In accordance with largely invariant OMC interactions, $\Delta \Delta \mathrm{G}^{\circ, /}$ was small for $\alpha \mathrm{IIb}(\mathrm{G} 972 \mathrm{~A})$ with 

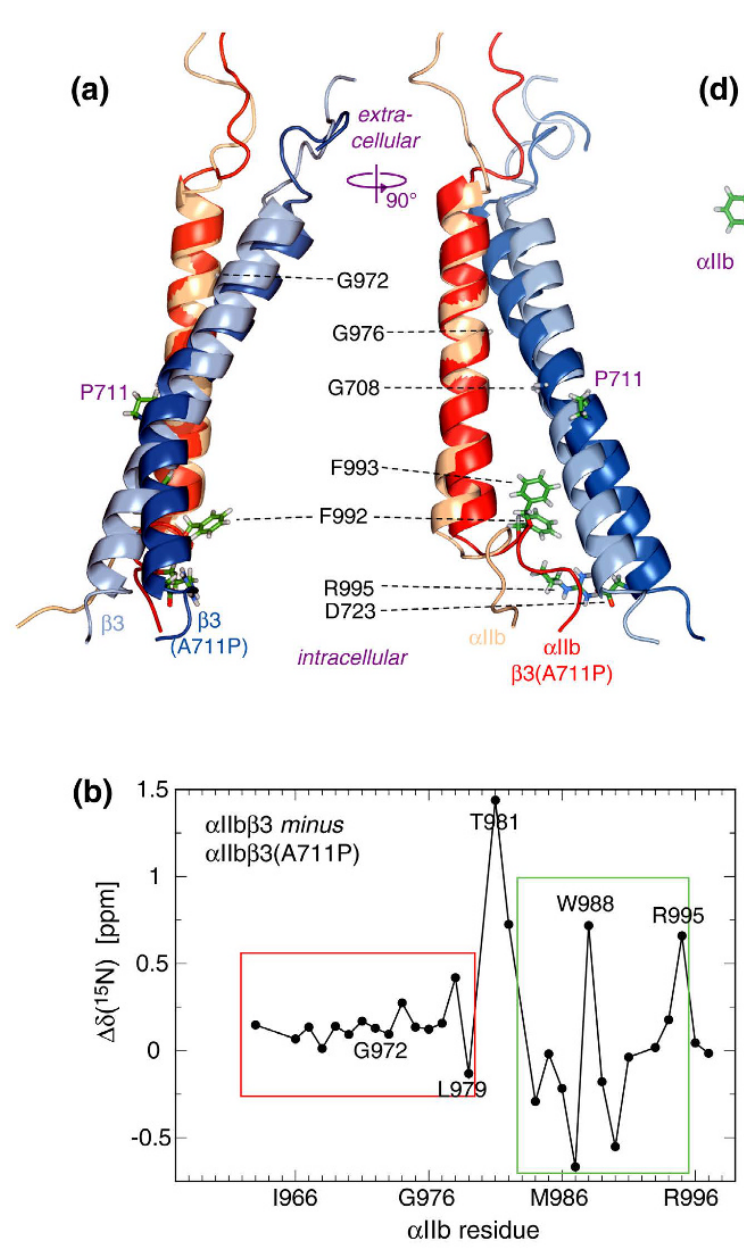

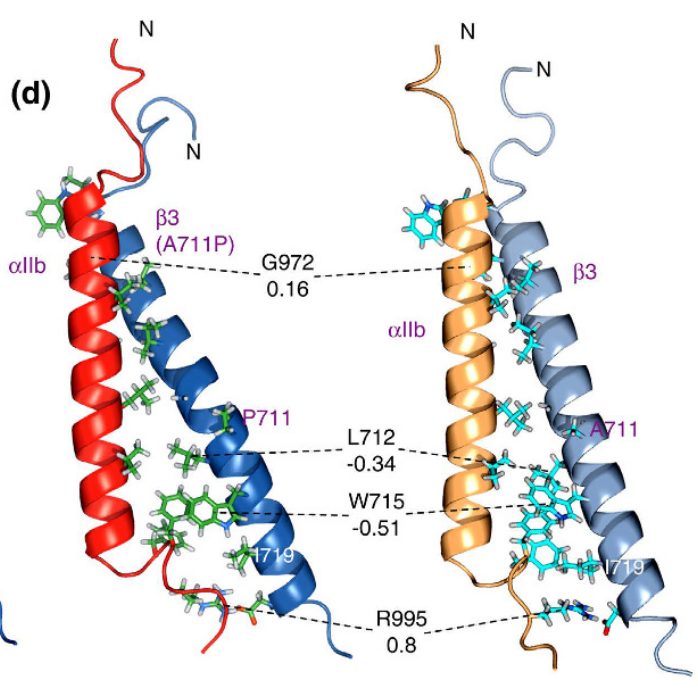

(c)

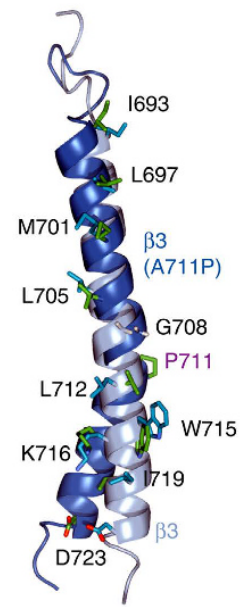

Figure 3. Structure of the integrin $\alpha \operatorname{IIb} \beta 3($ A711P) TM complex. (a) Comparison of integrin $\alpha \operatorname{IIb} \beta 3(\mathrm{~A} 711 \mathrm{P})$ and $\alpha I I b \beta 3$ TM complex structures. The structures were superimposed on the backbone heavy atoms of $\alpha I I b$ (W967-L979). (b) Chemical shift differences between $\alpha$ IIb backbone ${ }^{15} \mathrm{~N}$ nuclei of non-covalently linked $\alpha \operatorname{IIb} \beta 3(\mathrm{~A} 711 \mathrm{P})$ and $\alpha \mathrm{IIb} \beta 3 \mathrm{TM}$ complexes. (c) Comparison of $\beta 3$ sidechain orientations in the $\alpha \operatorname{IIb} \beta 3(\mathrm{~A} 711 \mathrm{P})$ and $\alpha \mathrm{IIb} \beta 3$ TM complex structures. TM complex coordinates were superimposed as shown in panel $a$. (d) Comparison of $\alpha \mathrm{IIb}(\mathrm{G} 972), \beta 3$ (L712), $\beta 3$ (W715) and $\alpha \mathrm{IIb}(\mathrm{R} 995)$ sidechain interactions between $\alpha$ $\operatorname{IIb} \beta 3(\mathrm{~A} 711 \mathrm{P})$ and $\alpha \mathrm{IIb} \beta 3$ TM complex structures. $\Delta \Delta \mathrm{G}^{\circ, /}$ associated with the $\alpha \operatorname{IIb}(\mathrm{G} 972 \mathrm{~A}), \beta 3(\mathrm{~L} 712 \mathrm{~A}), \beta$ 3 (W715Y) and $\alpha \operatorname{IIb}(\mathrm{R} 995 \mathrm{~A})$ substitutions (Table 1) are indicated. (e) Comparison of $\beta 3$ sidechain orientations when superimposing $\beta 3$ backbone coordinates near the TM termini. PDB entries $2 \mathrm{k} 9 \mathrm{j}(\alpha \operatorname{IIb} \beta 3)$ and $2 \mathrm{n} 9 \mathrm{y}$ $(\alpha \operatorname{IIb} \beta 3(\mathrm{~A} 711 \mathrm{P}))$ were used.

$0.16 \pm 0.03 \mathrm{kcal} / \mathrm{mol}$ (Fig. $3 \mathrm{~d}$ and Table 1 ). In the IMC, the swivel for 33 (L712) centered its sidechain more directly in the dimerization interface (Fig. $3 \mathrm{c}, \mathrm{d}$ ) and a $\Delta \Delta \mathrm{G}^{\circ, \prime}$ of $-0.34 \pm 0.01 \mathrm{kcal} / \mathrm{mol}$ revealed improved sidechain packing. Interestingly, $\beta 3$ (W715) moved in such a way that its pyrrole ring position in $\alpha \operatorname{IIb} \beta 3$ was replaced by its benzene ring in $\alpha \operatorname{IIb} 33(\mathrm{~A} 711 \mathrm{P})$ (Fig. 3c). This swap heightened hydrophobic interactions with $\alpha \mathrm{IIb}(\mathrm{Phe} 993)$ and, with $\Delta \Delta G^{\circ, I}=-0.51 \pm 0.04 \mathrm{kcal} / \mathrm{mol}$ for $\beta 3(\mathrm{~W} 715 \mathrm{Y})$, contributed to TM complex stabilization. The swivel of the IMC helix segment of $\beta 3$ rotated Lys716 towards the dimerization interface (Fig. 3c), which allows more favorable hydrogen bonding with $\alpha \mathrm{IIb}(\mathrm{Phe} 992 / \mathrm{CO})$ relative to the wild-type structure. Unfortunately, the strongly destabilizing nature of $\beta 3(\mathrm{~K} 716)$ substitutions ${ }^{18}$ did not allow the direct quantification of $\Delta \Delta \mathrm{G}^{\circ, \prime}$ at this site. $\beta 3$ (Ile719) engages in hydrophobic packing below the wedged aromatic rings and its increased distance from $\alpha I I b$ in the $\alpha \operatorname{IIb} \beta 3(\mathrm{A711P}) \mathrm{TM}$ complex is expected to be destabilizing (Fig. 3d). Likewise, the increased distance of $\beta 3(D 723)$ from $\alpha I I b$ requires an adjustment of the $\alpha I I b$ backbone conformation to make electrostatic contacts with $\alpha \mathrm{IIb}$ (R995) (Fig. 3d). $\Delta \Delta \mathrm{G}^{\circ, I}$ of $0.8 \pm 0.2 \mathrm{kcal} / \mathrm{mol}$ for $\alpha \mathrm{IIb}(\mathrm{R} 995 \mathrm{~A})$ confirmed the destabilizing nature of this adjustment.

As is the case with $\beta 3(\mathrm{~A} 711 \mathrm{P})$, prolines in membrane protein structures are frequently encountered near the center of TM helices ${ }^{4,22,23}$. Based on the $\alpha \mathrm{IIb} \beta 3(\mathrm{~A} 711 \mathrm{P}) \mathrm{TM}$ complex structure, we propose a general scheme for incorporating proline kinks in membrane proteins: maintain interhelical packing close to the proline kink and predominantly repack either the helix segment preceding or succeeding the kink. In case of $\alpha I I b \beta 3$, the OMC with glycine packing interactions was largely maintained (Fig. 3a,b), which is likely of general validity due to the 
high structural specificity of this interaction. With respect to $\beta 3(\mathrm{G} 708)$, A711P created a GXXP motif. Proline generally kinks away from the H-bond that is lost (Fig. 3c $)^{4}$, which makes the GXXP spacing well suited for heterodimeric helix-helix packing. In the repacked helix segment, the increasing separation of interhelical interactions tends to diminish interhelical contacts. To achieve a net stabilization of helix-helix interactions, contacts that remain within sidechain packing distances must be optimized and, evidently, the gain in stability must supersede the destabilization from compromised sidechain contacts. In case of $\alpha \operatorname{IIb} \beta 3(\mathrm{~A} 711 \mathrm{P})$, interactions within two helix turns C-terminal to the proline substitution were optimized (Fig. 3d and Table 1). Additionally, based on the $\beta 3$ (A711P)-induced chemical shift changes of $\alpha \mathrm{IIb}$ (Fig. 3b), favorable contributions from any repacking of $\beta$ 3(G708) with $\alpha \mathrm{IIb}$ (L980) cannot be excluded.

The alternative to maintaining interhelical contacts near the proline kink would be to preserve interactions at the TM helix termini. When inspecting this possibility for $\alpha \operatorname{IIb} \beta 3(\mathrm{~A} 711 \mathrm{P})$, it is apparent that mostly $\alpha \mathrm{IIb}$ (R995)- $\beta 3$ (D723) benefits whereas packing on $\beta 3$ (G708) and $\alpha \mathrm{IIb}(\mathrm{G} 976)$ would be less intimate (Fig. 3e). This mode of interaction appears generally inferior as it creates a packing void at the $\beta 3$ helix centre that is difficult to fill even when more TM helices were to be added. Despite the relatively complex and extensive packing of the integrin $\alpha$ IIb $\beta 3$ TM complex (Fig. 3), $\beta 3$ (A711P) revealed that it is not as well packed as possible. This is perhaps not surprising for two reasons. First, to accomplish the allosteric regulation of the receptor, $\Delta \mathrm{G}^{\circ}{ }_{\mathrm{TM}}$ must be balanced with the affinity of intra- and extracellular receptor agonists and with the stability of the inactive versus the active ectodomains ${ }^{15,24}$. Secondly, the increase in $\Delta G^{\circ}$ TM came at the expense of $\alpha \operatorname{IIb}(R 995)-\beta 3(D 723)$ destabilization. This interaction is disrupted during talin-mediated integrin activation ${ }^{25}$. With its reduced importance for TM complex stability in $\alpha \operatorname{IIb} \beta 3(\mathrm{~A} 711 \mathrm{P})$, talin is now unable to activate the receptor in its presence ${ }^{26}$. In sum, we have revealed the structural and thermodynamic requirements for incorporating proline into TM helix-helix interactions and gained insight into constraints that underlie the evolution of such kinks.

\section{Methods}

NMR spectroscopy. The disulfide-linked $\alpha \mathrm{IIb}($ A963C)- $33(\mathrm{G} 690 \mathrm{C} / \mathrm{A} 711 \mathrm{P})$ dimer was prepared applying published protocols ${ }^{20}$ and incorporated human integrin sequences $\alpha \mathrm{IIb}(\mathrm{A} 958-\mathrm{P} 998)$ and $\beta 3$ (P685-F727) with $\beta 3$ (C687S). Perdeuterated peptides were produced using $99 \% \mathrm{~d}_{7}$-glucose, $99 \%{ }^{15} \mathrm{ND}_{4} \mathrm{Cl}$ and $99 \% \mathrm{D}_{2} \mathrm{O}$. A fractionally deuterated ${ }^{2} \mathrm{H} /{ }^{13} \mathrm{C} /{ }^{15} \mathrm{~N}-\alpha \mathrm{IIb}(\mathrm{A} 963 \mathrm{C})-\beta 3(\mathrm{G} 690 \mathrm{C} / \mathrm{A} 711 \mathrm{P})$ sample was prepared by growing $E$. coli cells in $60 \% \mathrm{D}_{2} \mathrm{O}$ using protonated precursors. Freeze-dried peptide was reconstituted in $320 \mu \mathrm{L}$ of $350 \mathrm{mM} \mathrm{1,2-dihex-}$ anoyl-sn-glycero-3-phosphocholine (DHPC), $105 \mathrm{mM}$ 1,2-dimyristoyl-sn-glycero-3-phosphocholine (DMPC), $6 \% \mathrm{D}_{2} \mathrm{O}, 0.02 \% \mathrm{w} / \mathrm{v} \mathrm{NaN} \mathrm{Naffered}_{3}$ by either $25 \mathrm{mM} \mathrm{NaH}_{2} \mathrm{PO}_{4} / \mathrm{Na}_{2} \mathrm{HPO}_{4}, \mathrm{pH} 7.4$ or $25 \mathrm{mM} \mathrm{HEPES} \cdot \mathrm{NaOH}, \mathrm{pH}$ 7.4 for a final concentration of $0.8 \mathrm{mM}$ and bicelle q-factor of 0.3 .

Starting from the ${ }^{1} \mathrm{H}^{\mathrm{N}},{ }^{15} \mathrm{~N},{ }^{13} \mathrm{C}^{\alpha},{ }^{13} \mathrm{C}^{\beta}$, and ${ }^{13} \mathrm{C}^{\prime}$ assignment of the $\alpha \operatorname{IIb} \beta 3 \mathrm{TM}$ complex and the $\beta 3$ (A711P/K716A) TM segment ${ }^{15,18}$, backbone assignments of ${ }^{2} \mathrm{H} /{ }^{13} \mathrm{C} /{ }^{15} \mathrm{~N}-\alpha \operatorname{IIb}(\mathrm{A} 963 \mathrm{C})-{ }^{2} \mathrm{H} /{ }^{13} \mathrm{C} /{ }^{15} \mathrm{~N}-\beta 3$ (G690C/A711P) were achieved employing HNCA, HNCO, HNCACB and NOESY-TROSY experiments. ${ }^{15} \mathrm{~N}$-edited NOESY-TROSY experiments using ${ }^{2} \mathrm{H} /{ }^{15} \mathrm{~N}-\alpha \operatorname{IIb}(\mathrm{A} 963 \mathrm{C})-\beta 3(\mathrm{G} 690 \mathrm{C} / \mathrm{A} 711 \mathrm{P})$ or $\alpha \operatorname{IIb}(\mathrm{A} 963 \mathrm{C})-$ ${ }^{2} \mathrm{H} /{ }^{15} \mathrm{~N}-\beta 3$ (G690C/A711P) dimers were acquired with mixing times of 120,150 and $175 \mathrm{~ms}$. Using [60\% $\left.{ }^{2} \mathrm{H}\right] /{ }^{13} \mathrm{C} /{ }^{15} \mathrm{~N}-\alpha \operatorname{IIb}(\mathrm{A} 963 \mathrm{C})-\beta 3(\mathrm{G} 690 \mathrm{C} / \mathrm{A} 711 \mathrm{P})$, an aromatic ${ }^{13} \mathrm{C}$-edited NOESY-HSQC experiment (mixing time $150 \mathrm{~ms}$ ) was recorded. Sidechain assignments started again from the $\alpha \operatorname{IIb} \beta 3$ TM complex and were similar to the aforementioned NOESY spectra. In a general case, NOESY experiments for ${ }^{2} \mathrm{H} /{ }^{14} \mathrm{~N}-\alpha-{ }^{1} \mathrm{H} /{ }^{15}-\beta$ and ${ }^{1} \mathrm{H} /{ }^{15} \mathrm{~N}-\alpha$ ${ }^{2} \mathrm{H} /{ }^{14}-\beta$ can establish sidechain assignments in combination with standard experiments. Sidechain and NOE assignments were carried out manually using the program CARA. H-N residual dipolar couplings (RDC) were measured twice in compressed polyacrylamide gels (scalar product 0.983 ) using ${ }^{2} \mathrm{H} /{ }^{15} \mathrm{~N}-\alpha \mathrm{IIb}(\mathrm{A} 963 \mathrm{C})-{ }^{2} \mathrm{H} /{ }^{15} \mathrm{~N}-\beta 3$ (G690C/A711P) dimer ${ }^{20}$. All NMR experiments were carried out on a cryoprobe-equipped Bruker Avance 700 spectrometer at $40^{\circ} \mathrm{C}$.

Structure calculation of the integrin $\alpha$ Ilb $\beta 3(A 711 P)$ TM complex. Structure calculations were carried out by simulated annealing, starting at $3000 \mathrm{~K}$ using the program XPLOR-NIH ${ }^{27}$. Backbone torsion angle restraints were extracted from ${ }^{15} \mathrm{~N},{ }^{13} \mathrm{C}^{\alpha},{ }^{13} \mathrm{C}^{\beta}$, and ${ }^{13} \mathrm{C}^{\prime}$ chemical shift patterns ${ }^{28}$. Within experimental uncertainties, H-N RDCs measured for the $\alpha I I b \beta 3(A 711 P)$ TM dimer fitted the $\alpha I I b$ and $\beta 3(A 711 \mathrm{P} / \mathrm{K} 716 \mathrm{~A})$ TM monomer structures ${ }^{20}$. This congruence permitted the use of $\mathrm{H}-\mathrm{N}, \mathrm{C}^{\alpha}-\mathrm{C}^{\prime}, \mathrm{N}-\mathrm{C}^{\prime} \mathrm{RDCs}$ measured for these monomers to further restrict the individual $\alpha \mathrm{IIb}$ and $\beta 3(\mathrm{~A} 711 \mathrm{P})$ backbone conformations. An employed torsion angle potential of mean force ${ }^{29}$ was biased to use the experimental $\chi_{1}$ angles detected in the monomeric $\alpha \mathrm{II} b$ and $\beta$ 3(A711P/K716A) TM segments, which mostly corresponded to their default values. Moreover, the sidechains of $\alpha \mathrm{IIb}$ (Phe992) and $\beta 3$ (Lys716) were adjusted to snorkel. Aside from standard force field terms for covalent geometry (bonds, angles, and improper dihedrals) and nonbonded contacts (Van der Waals repulsion), dihedral angle restraints were implemented using quadratic square-well potentials. In addition, a backbone-backbone hydrogen-bonding potential was employed ${ }^{30}$. A quadratic harmonic potential was used to minimize the difference between predicted and experimental residual dipolar couplings (RDC; $\Delta^{1} D$ ). The final values for the force constants of the different terms in the simulated annealing target function were as previously described ${ }^{15}$. Supplementary Table 1 summarizes the structural statistics for all 20 calculated structures. The structures together with the energy-minimized average structure and structural constraints have been deposited in the Protein Data Bank and BMRB with accession numbers 2n9y and 25920, respectively.

Isothermal titration calorimetry. ITC measurements of the peptides listed in Table 1 were carried on a Microcal VP-ITC calorimeter. $10 \mu \mathrm{M}$ of $\beta 3$ peptide in the $1.425 \mathrm{ml}$ sample cell was titrated with $\alpha \mathrm{IIb}$ peptide by injecting $9 \mu \mathrm{l}$ aliquots over a period of $10 \mathrm{~s}$ each. Measurements were carried out in $43 \mathrm{mM}$ 1,2-dihexanoly-sn-glycero-3-phosphocholine (DHPC), $17 \mathrm{mM}$ 1-palmitoyl-2-oleoyl-sn-glycero-3-phosphocholine 
(POPC), $25 \mathrm{mM} \mathrm{NaH}_{2} \mathrm{PO}_{4} / \mathrm{Na}_{2} \mathrm{HPO}_{4} \mathrm{pH} 7.4$ at $28^{\circ} \mathrm{C}$. Prior to data analysis, the measurements were corrected for the heat of dilutions of the $\alpha$ IIb and $\beta 3$ peptides. The $\alpha \operatorname{IIb} \beta 3$ complex stoichiometry was fixed at $1: 1^{31}$ and the reaction enthalpy $\left(\Delta \mathrm{H}^{\circ}\right)$ and $\mathrm{K}_{\mathrm{XY}}$ were calculated from the measured heat changes, $\delta \mathrm{H}_{\mathrm{i}}$, as described previously ${ }^{31}$. The entropy change, $\Delta \mathrm{S}^{\circ}$, is obtained as $\left(\Delta \mathrm{H}^{\circ}-\Delta \mathrm{G}^{\circ}\right) / \mathrm{T}$.

\section{References}

1. Todd, A. E., Orengo, C. A. \& Thornton, J. M. Evolution of function in protein superfamilies, from a structural perspective. J Mol Biol 307, 1113-1143 (2001).

2. Hynes, R. O. The evolution of metazoan extracellular matrix. J Cell Biol 196, 671-679 (2012).

3. Schimmel, P. R. \& Flory, P. J. Conformational Energies And Configurational Statistics Of Copolypeptides Containing L-Proline. J Mol Biol 34, 105-120 (1968).

4. Cordes, F. S., Bright, J. N. \& Sansom, M. S. P. Proline-induced distortions of transmembrane helices. J Mol Biol 323, 951-960 (2002).

5. Li, S. C., Goto, N. K., Williams, K. A. \& Deber, C. M. alpha-Helical, but not beta-sheet, propensity of proline is determined by peptide environment. Proc Natl Acad Sci USA 93, 6676-6681 (1996).

6. Senes, A., Engel, D. E. \& DeGrado, W. F. Folding of helical membrane proteins: the role of polar, GxxxG-like and proline motifs. Curr Opin Struct Biol 14, 465-479 (2004).

7. Deupi, X., Olivella, M., Govaerts, C., Ballesteros, J. A. \& Campillo, M., Pardo L. Ser and Thr residues modulate the conformation of pro-kinked transmembrane alpha-helices. Biophys J 86, 105-115 (2004).

8. Langelaan, D. N., Wieczorek, M., Blouin, C. \& Rainey, J. K. Improved Helix and Kink Characterization in Membrane Proteins Allows Evaluation of Kink Sequence Predictors. J Chem Inf Model 50, 2213-2220 (2010)

9. Hall, S. E., Roberts, K. \& Vaidehi, N. Position of helical kinks in membrane protein crystal structures and the accuracy of computational prediction. J Mol Graph 27, 944-950 (2009).

10. Yohannan, S., Faham, S., Yang, D., Whitelegge, J. P. \& Bowie, J. U. The evolution of transmembrane helix kinks and the structural diversity of G protein-coupled receptors. Proc Natl Acad Sci USA 101, 959-963 (2004).

11. Wigley, W. C. et al. A protein sequence that can encode native structure by disfavoring alternate conformations. Nat Struct Biol 9 , 381-388 (2002).

12. Partridge, A. W., Therien, A. G. \& Deber, C. M. Missense mutations in transmembrane domains of proteins: Phenotypic propensity of polar residues for human disease. Proteins-Structure Function And Bioinformatics 54, 648-656 (2004).

13. Yohannan, S., Yang, D., Faham, S., Boulting, G., Whitelegge, J. \& Bowie, J. U. Proline substitutions are not easily accommodated in a membrane protein. J Mol Biol 341, 1-6 (2004).

14. Orzaez, M., Salgado, J., Gimenez-Giner, A., Perez-Paya, E. \& Mingarro, I. Influence of proline residues in transmembrane helix packing. J Mol Biol 335, 631-640 (2004).

15. Lau, T.-L., Kim, C., Ginsberg, M. H. \& Ulmer, T. S. The structure of the integrin alphaIIbbeta3 transmembrane complex explains integrin transmembrane signalling. EMBO J 28, 1351-1361 (2009).

16. Hughes, P. E. et al. Breaking the integrin hinge - A defined structural constraint regulates integrin signaling. J Biol Chem 271, 6571-6574 (1996).

17. Jayo, A. et al. L718P mutation in the membrane-proximal cytoplasmic tail of beta 3 promotes abnormal alpha IIb beta 3 clustering and lipid microdomain coalescence, and associates with a thrombasthenia-like phenotype. Haematol-Hematol J 95, 1158-1166 (2010).

18. Kim, C., Schmidt, T., Cho, E. G., Ye, F., Ulmer, T. S. \& Ginsberg, M. H. Basic amino-acid side chains regulate transmembrane integrin signalling. Nature 481, 209-212 (2012).

19. Triba, M. N., Warschawski, D. E. \& Devaux, P. F. Reinvestigation by phosphorus NMR of lipid distribution in bicelles. Biophys J 88, 1887-1901 (2005).

20. Suk, J. E., Situ, A. J. \& Ulmer, T. S. Construction of Covalent Membrane Protein Complexes and High-throughput Selection of Membrane Mimics. J Am Chem Soc 134, 9030-9033 (2012).

21. Ulmschneider, M. B. \& Sansom, M. S. P. Amino acid distributions in integral membrane protein structures. Biochim Biophys ActaBiomembr 1512, 1-14 (2001).

22. Landoltmarticorena, C., Williams, K. A., Deber, C. M. \& Reithmeier, R. A. F. Nonrandom Distribution Of Amino-Acids In The Transmembrane Segments Of Human Type-I Single Span Membrane-Proteins. J Mol Biol 229, 602-608 (1993).

23. Mokrab, Y., Stevens, T. J. \& Mizuguchi, K. A structural dissection of amino acid substitutions in helical transmembrane proteins. Proteins-Structure Function And Bioinformatics 78, 2895-2907 (2010).

24. Grigoryan, G., Moore, D. T. \& DeGrado, W. F. Transmembrane Communication: General Principles and Lessons from the Structure and Function of the M2 Proton Channel, K+ Channels, and Integrin Receptors. In: Annual Review Of Biochemistry, Vol 80 (ed^(eds). Annual Reviews (2011).

25. Anthis, N. J. et al. The structure of an integrin/talin complex reveals the basis of inside-out signal transduction. EMBO J 28, 3623-3632 (2009).

26. Kim, C. H., Ye, F., Hu, X. H. \& Ginsberg, M. H. Talin activates integrins by altering the topology of the beta transmembrane domain. JCell Biol 197, 605-611 (2012).

27. Schwieters, C. D., Kuszewski, J. J., Tjandra, N. \& Clore,, G. M. The Xplor-NIH NMR molecular structure determination package. J Magn Reson 160, 65-73 (2003).

28. Shen, Y., Delaglio, F., Cornilescu, G. \& Bax, A. TALOS plus: a hybrid method for predicting protein backbone torsion angles from NMR chemical shifts. J Biomol NMR 44, 213-223 (2009).

29. Kuszewski, J. J. \& Clore, G. M. Sources of and solutions to problems in the refinement of protein NMR structures against torsion angle potentials of mean force. J Magn Reson 146, 249-254 (2000).

30. Grishaev, A. \& Bax, A. An empirical backbone-backbone hydrogen-bonding potential in proteins and its applications to NMR structure refinement and validation. J Am Chem Soc 126, 7281-7292 (2004).

31. Situ, A. J., Schmidt, T., Mazumder, P. \& Ulmer, T. S. Characterization of Membrane Protein Interactions by Isothermal Titration Calorimetry. J Mol Biol 426, 3670-3680 (2014).

32. Schmidt, T. et al. Annular Anionic Lipids Stabilize the Integrin alpha IIb beta 3 Transmembrane Complex. J Biol Chem 290, 8283-8293 (2015).

33. Egloff, P. et al. Structure of signaling-competent neurotensin receptor 1 obtained by directed evolution in Escherichia coli. Proc Natl Acad Sci USA 111, E655-E662 (2014).

\section{Acknowledgements}

This work was supported by American Heart Association grant 15GRNT23200010.

\section{Author Contributions}

T.S. and T.S.U. collected and analyzed NMR data and performed structure calculations. A.J.S. collected and analyzed ITC data. T.S.U. prepared the manuscript with input from all authors. 


\section{Additional Information}

Supplementary information accompanies this paper at http://www.nature.com/srep

Competing financial interests: The authors declare no competing financial interests.

How to cite this article: Schmidt, T. et al. Structural and thermodynamic basis of proline-induced transmembrane complex stabilization. Sci. Rep. 6, 29809; doi: 10.1038/srep29809 (2016).

(c) (i) This work is licensed under a Creative Commons Attribution 4.0 International License. The images or other third party material in this article are included in the article's Creative Commons license, unless indicated otherwise in the credit line; if the material is not included under the Creative Commons license, users will need to obtain permission from the license holder to reproduce the material. To view a copy of this license, visit http://creativecommons.org/licenses/by/4.0/ 